\title{
Determination of shear modulus and Poisson's ratio of polymers and foams by the anticlastic plate-bending method
}

\author{
M. Farshad ${ }^{1}$, M. W. Wildenberg ${ }^{2}$ and P. Flüeler ${ }^{3}$ \\ (1) Section Polymers/Composites, EMP.A Dïbendorf, Titular Proffssor ETHZ, Siwitzerland

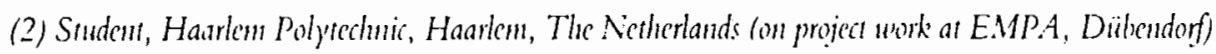 \\ (3) Section Polymers/Composites, EMP.4 Dïbendorf. Lecturer ETHZ, Suitizerland
}

\section{A B S T R A C T}

In this paper. results of research towards development of a test method for the determination of shear modulus and Poisson's ratio of polymers and structural foams are presented. Through this work, a test apparatus was developed which employed anticlastic plate bending behaviour; this device was used for calibration tests on steel and aluminium samples and for tests on a number of polymers, including high density Polyethylene (PE-HD). unplasticized Polyvinylchloride (PVC-U), Polymethylmethacrylate (PMMA) and rigid Polyurethane (PUR) foam. Long-term tests and temperature-dependent tests on PVC-U, PE-HD and PMMA samples were also performed. In some cases, results of the tests with the anticlastic bending method were compared with those obtained from tests carried out with the torsion pendulum method. For theoretical simulation, an analytical formula and a number of finite element analyses were performed. Through these simulations, values for the short-term, long-term and temperature-dependent shear modulus and Poisson's ratio of PE-HD, PMMA, PVC-U and PUR foam were obtained.

\section{INTRODUCTION}

Shear modulus and Poisson's ratio of various polymers and rigid foams are needed for the design of structural and composite elements. For these materials, not only the knowledge of the short-term properties, but also information about their long-term, temperaturedependent behaviour is of importance.

In this paper. a well-known testing methodology for determining the short-term and long-term shear moduli and Poisson's ratios of polymers and foams is introduced. This testing system is referred to as the Anticlastic Plate-
R É SU M É

On présente les résultats des trataux sur le développement d'une méthode d'essai pour la détermination des coefficients d'élasticití en cisaillement et des coefficients de Poisson des polymeres et des mousses structurales. On a concu un apparcil d'essais utilisan le comportement en flexion anticlastique de plaques. Cot appareil a été urilisé pour des essais de calibration des échantillons d'acier et d'aluminimm, ainsi que pour des cssais sur des polymères, y compris le polyétlylène à haute densité (PEHD), le chlorure de polyuningle non plastifić (PVC-U), le polyméthacrylate de métlyyle (PMMA) et la mousse rigide en polyuréthanne (PUR). Des essais de longue durée et de dépendance de la températurc ont également été réalisés sur les échantillons de PVC-U, de PE-HD et de PMMA. Dans cortains cas, les résultats des essais par la méthode de flexion anticlastigue ont été comparés aux résultats obtenus par la méthode de pendule de torsion. Line simulation théorique basée sur une formule analytique et un certain nombre d'analyses au éléments finis a été réalisié Grâce à ces simulations, les valeurs des coefficients d'élasticité et de Poisson - à court terme, à long terme et dépendantes de la température - ont pu cetre obtenues pour le PE-HD, le PMMA, lo PIC-U a la mousse PUR.

Bending ( $\mathrm{ACPB}$ ) method. The ACPB testing methodology is based on the knowledge that a rectangular plate subjected to a torsional couple will undergo an anticlastic bending and will assume a saddle shape [1]. This behaviour is strongly dependent on the in-plane shear properties of the constituent material; hence, by understanding this phenomenon, it would be possible to devise a testing device with which - and with the help of a proper theoretical correlation - the shear modulus in the plane of the plate may be determined. A similar methodology has been applied to find the shear modulus of plywood ([2] and $[3])$. 
In the first part of this paper. a simple theoretical model for the anticlastic bending of rectangular plates is outlined. In addition to this analytical modelling, a Finite Element (FE) simulation is also carried out. Then, an experimental set-up for the determination of short-term and long-term shear moduli is introduced, and the stages in its design and development are briefly described.

Other parts of the paper include the results of the short-term tests on a high-density Polyethylene (PEHD), an unplasticized Polyvinylchloride (PVC-U), Polymethylmethacrylate (PMMA), and a rigid Polyurethane foam (PUR) along with the results of their experimental and theoretical correlation. Morcover, the results of the long-term and temperature-dependent tests on PVC-U, PE-HD and PMMA are reported. In some cases, independent tests have also been conducted on the same materials with the torsion pendulum and the tensile test methods. The results of these tests are correlated with those of the ACPB tests; through this comparison, correlation factors are obtained.

\section{ANTICLASTIC BENDING OF PLATES}

\subsection{Anticlastic bending behaviour}

An anticlastic plate-bending (ACPB) of a thin elastic rectangular plate is a mode of deformation in which the plate assumes a saddle shape containing two opposing principal curvatures. To produce an anticlastic deformation, one may apply two equal but opposite uniformlydistributed bending moments $M_{x}=-M_{v}$ along the two pairs of intersecting edges (Fig. 1a). An ACPB behaviour can also be produced by applving a uniformly-distributed torsional couple along the edges. This loading is statically equivalent to two pairs of corner forces which are applied at two diagonal corners (Fig. 1b). The value of the corner forces equals twice the distributed rwisting couple [4]. The result of both of the above-mentioned loading types is a general twist in the xy-direction; twist-
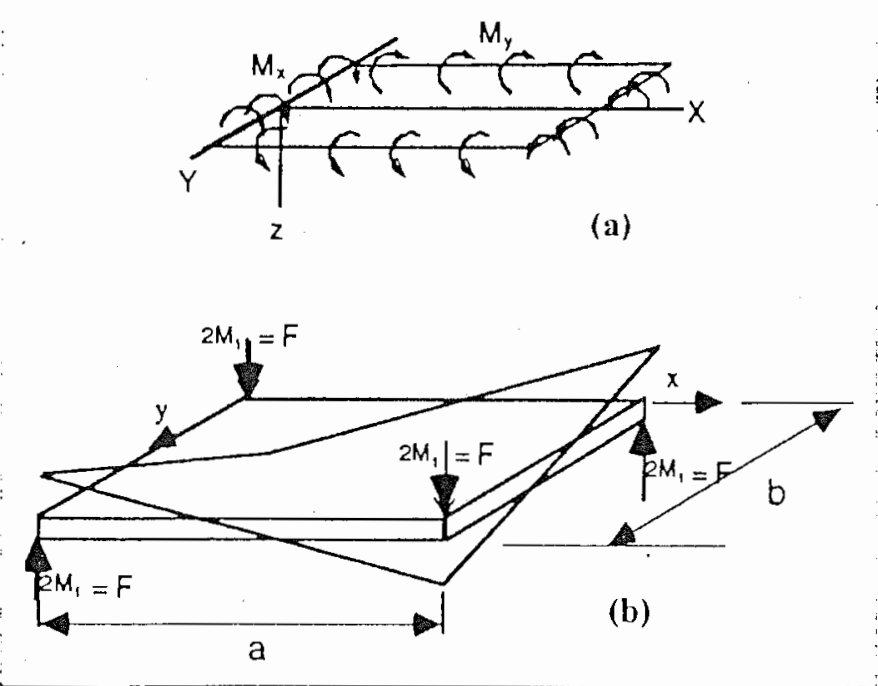

Fig. 1 - (a) Applied opposite moments on a rectangular plate to induce anticlastic bending; (b) applied corner forces. ing of the plate causes a dominanty shear field which may be advantageously related to the torsional rigidicy or the shear modulus of the constituent material.

\subsection{Anticlastic plate-bending formula}

From classical plate theory, the corner detlection of a square plate loaded by concentrated forces applied at its four corners can be derived as:

$$
\Delta=\frac{F^{2}}{4 D(1-\nu)}
$$

where $\mathrm{F}$ is the force applied at each comer (total force $\mathrm{W}$ applied to the plate is $W=2 \mathrm{~F}$ ), $\mathrm{a}$ is the side dimension of the plate, and $\mathrm{D}$ is the bending stiffness of the plate which is defined by:

$$
\mathrm{D}=\frac{\mathrm{Eh}^{3}}{12\left(1-v^{2}\right)}
$$

where $h$ is the plate thickness, $E$ is the Young's modulus, and $v$ is the Poisson's ratio. Hence, the expression for the Poisson's ratio is:

$$
\nu=\frac{\mathrm{Eh}^{3} \Delta}{3 \mathrm{Fa}^{2}}
$$

For an isotropic material $G=E / 2(1+v)$; therefore, the shear modulus would be:

$$
\mathrm{G}=\frac{3 \mathrm{Fa}^{2}}{2 \Delta \mathrm{h}^{3}}
$$

For anisotropic materials, this method may be used to estimate the torsional rigidity of anisotropic plate samples [5].

Formula (4) is based on classical plate bending theory; it only considers bending effects decoupled from the in-plane stresses and neglects shear deformation. Correction due to shear deformation may be implemented [6]. In the present work, however, due to the choice of a thickness-to-width ratio of about 1/25. the shear deformation is expected to be insignificant.

\subsection{Finite element simulation}

For numerical simulation of experiments and for illustration of the shear stress field in the plate and corner effects, a Finite Element (FE) analysis was performed. The FE analysis was carried out on a square PVC-U plate for which a linear elastic and isotropic behaviour was assumed. For the finite element analysis. the following data were employed:

$a=b=100 \mathrm{~mm}, \mathrm{~h}=5 \mathrm{~mm}, E=2900) \mathrm{N}^{\prime} \mathrm{mm}^{2}, v=10.33$

The loading consisted of two concentrated forces each equal to $30 \mathrm{~N}$ applied normally to the plate surtace at diagonal corners. The other two diagonal corners were partially restrained against rotation and rransiarion. In Section 5, the results of the Finite Elenent analysis will be correlated with the experimental data. 

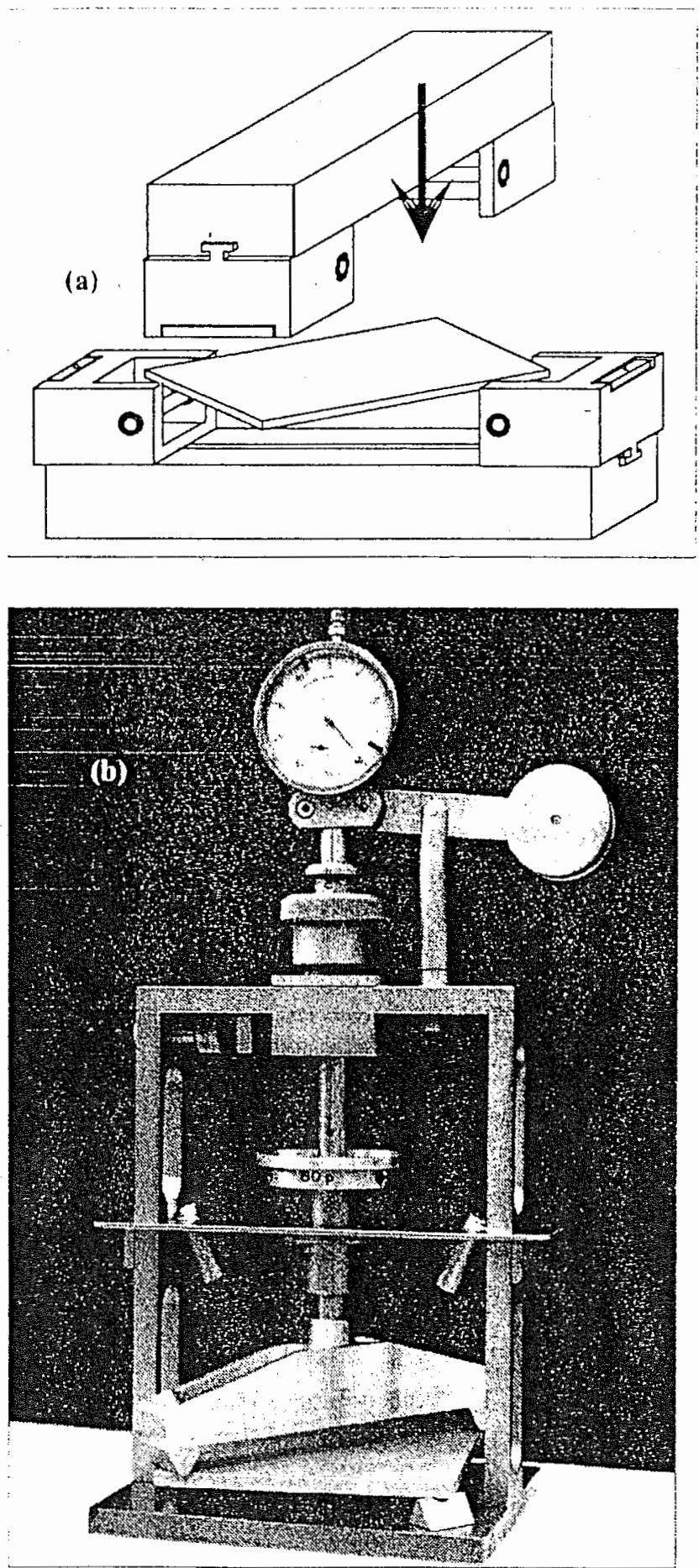

Fig. 2 - (a) A sketch of the ACPB device; (b) photograph of the $A C P B$ device.

\section{ACPB TESTING SYSTEM}

To achice an optimal ACPB testing srstem. various designe were conceived and constructed. One of these testing rigs consisted of a portable derice which could be flaced in the themal conditioning chamber and could also be used for the long-term (creep) rest. Another device could be used together with a standard tensioncompression resting machine. Fig. 2a shows schematicalle the principle of this ACPB testing device. Fig. 2h displave a photograph of the construced ersem. In

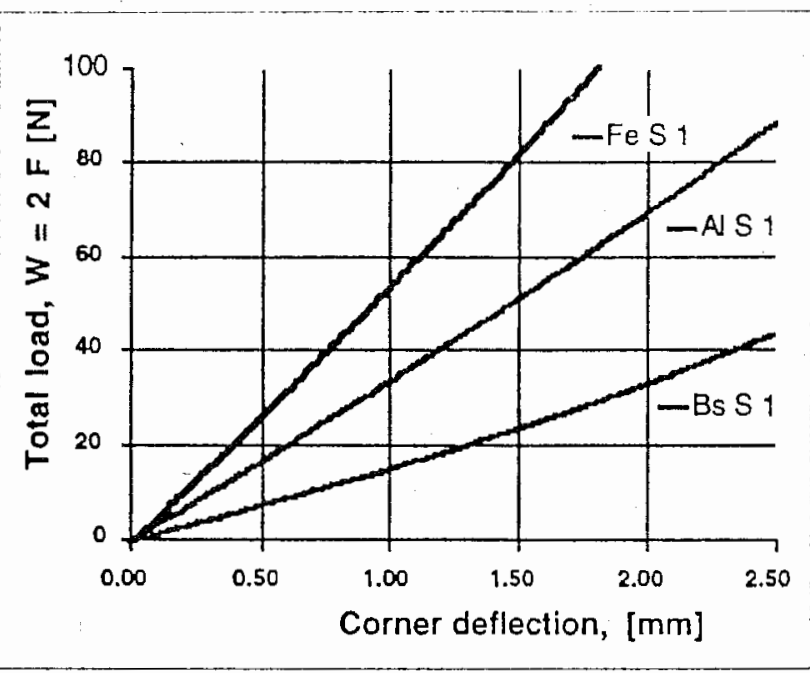

Fig. 3 - Load deflection curves for three metallic samples.

developing an optimal system. the effects of boundary conditions. sample size and the manner of load application were all experimentally investigated.

\section{CALIBRATION TESTS}

To assess the functionality of the testing system, a number of calibration tests were performed. These calibration tests included short-term ACPB tests on polvmers and foams, long-term tests. temperature-dependent tests, and comparison tests with the torsion pendulum testing method. Calibration tests were also carried out with the installed testing machine as well as with the portable testing device. Calibration samples consisted of steel, brass, and aluminium with known shear moduli: these moduli were determined br tensile tests. A number of pre-tests were also performed on the PVC-U samples. The calibration tests did lead to improvements in the design of the testing system and to construction of a device whose system errors were substantially reduced.

Fig. 3 shows an overview of the results of calibration tests on steel. aluminium and brass plates; these curves were used to calculate the shear moduli of the tested samples.

Table 1 presents the outcome of the calculation leading to the value of the shear modulus for aluminium and PVC-U; for this calculation, formula (4) was employed.

\begin{tabular}{|c|c|c|}
\hline \multicolumn{3}{|c|}{$\begin{array}{c}\text { Table } 1 \text { - Shear moduli obtained } \\
\text { with the ACPB device }\end{array}$} \\
\hline \multirow{2}{*}{ Materials and samples } & \multicolumn{2}{|c|}{ Shear modulus $\left[\mathrm{N} / \mathrm{mm}^{2}\right]$} \\
\hline & Reference values & ACPB \\
\hline Aluminium & 26,161 & 29,877 \\
\hline $\operatorname{PVC}(\mathrm{h}=2 \mathrm{~mm})$ & 1,380 & 1,630 \\
\hline$P V C(h=4 \mathrm{~mm})$ & 1,310 & 1,457 \\
\hline $\operatorname{PVC}(\mathrm{h}=5 \mathrm{~mm})$ & 1,300 & 1,345 \\
\hline
\end{tabular}




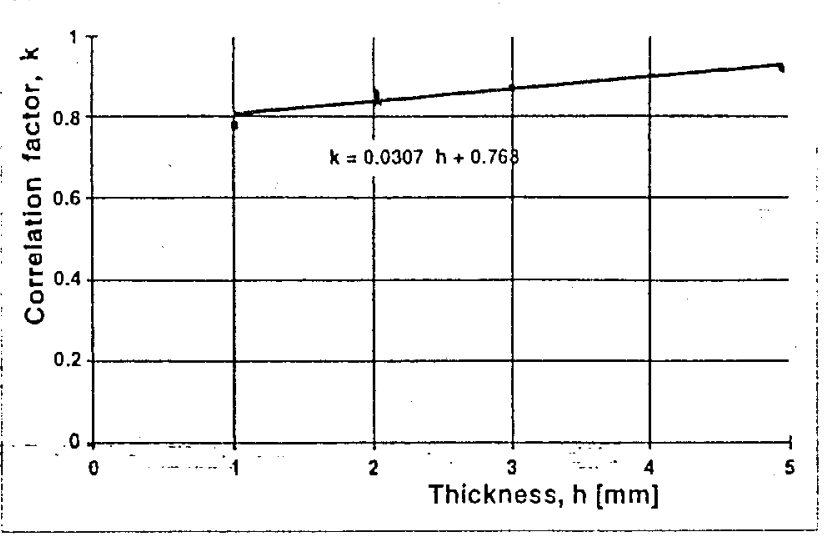

Fig. 4 - Variation of correction factor with plate thickness for aluminium samples.

This table includes values of the reference shear moduli for these materials which may be found in the classical literature [7].

To compare the test results obtained from the $\mathrm{ACPB}$ rig with those obtained from other methods, a series of tests were performed with the torsion pendulum method [8]. In addition, a number of tensile tests on strips of the same materials were also carried out; these samples were instrumented with a longitudinal and a lateral strain gauge. Thus, through tension testing the value of Poisson's ratio was estimated [9].

From calibration tests, a correlation factor $k$ was obtained. This correlation factor $k$ is defined as the ratio of the reference shear modulus $G_{R}$ to the shear modulus value $G_{A}$ obtained with the $A C P B$ test. The correlation factor is derived from the assumptions inherent in the $\mathrm{ACPB}$ theory (relation 4), the boundary and size effects, and the difference between the ACPB method and those related to the reference values.

$$
k=G_{\mathrm{R}} / G_{\mathrm{A}}
$$

The correlation factor $k$ is, in general, a function of the plate thickness: Fig. 4 shows the variation of the kfactor with plate thickness for aluminium samples. However, with reference to Fig. $f$, a linear thickness dependency for the k-factor may be assumed. Through linear curve-fitting, the following formula is derived:

$$
k=0.11307 h-0.768
$$

\section{Table 2 - Correlation factor calculated from}

\begin{tabular}{|c|c|c|c|c|}
\hline \multirow[b]{2}{*}{ Material } & \multirow[b]{2}{*}{$\begin{array}{c}\text { Thickness, } \\
\text { h [mm] }\end{array}$} & \multicolumn{2}{|c|}{ Shear modulus $\left[10^{3} \times \mathrm{N} / \mathrm{mm}^{2}\right]$} & \multirow[b]{2}{*}{$\begin{array}{c}\text { Correlation } \\
\text { factor, } k\end{array}$} \\
\hline & & $\begin{array}{c}\text { Comparison } \\
\text { values }\end{array}$ & $\begin{array}{l}\text { Anticlastic plate } \\
\text { bending }\end{array}$ & \\
\hline Steel & 1.009 & 82.0 & 105 & 0.78 \\
\hline Aluminium & 2.021 & 26.2 & 30.3 & 0.86 \\
\hline Brass & 2.029 & 40.0 & 47.8 & 0.84 \\
\hline Aluminium & 2.022 & 26.2 & 30.5 & 0.86 \\
\hline Aluminium & 2.993 & 26.0 & 29.8 & 0.87 \\
\hline Aluminium & 4.953 & 26.6 & 28.9 & 0.92 \\
\hline
\end{tabular}
the comparison values and the ACPB tests

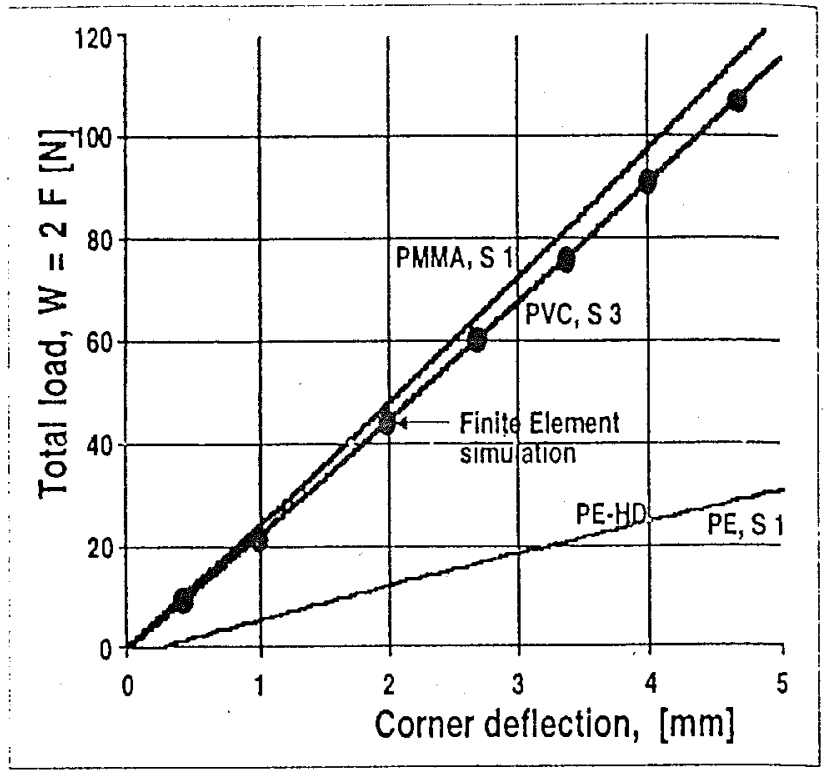

Fig. 5 - Load deflection curves for PVC, PE and PMMA.

If the correlation factor deduced from Fig. 4 is implemented in the classical relation for the corner-loaded plates, the correlated relation would read as follows:

$$
\mathrm{G}_{\mathrm{AC}}=\mathrm{k} \frac{3 \mathrm{Fa}^{2}}{2 \Delta \mathrm{h}^{3}}
$$

Table 2 presents the results of calibration tests which have led to deriving correlation factors.

\section{SHORT-TERM ACPB TESTS}

\subsection{Polymers}

Plate samples from PVC, PE-HD, and PMMA had dimensions of $110 \mathrm{~mm} \times 110 \mathrm{~mm} \times 5 \mathrm{~mm}$. The correlation factor for these materials ranged from 0.921 to 0.924. Fig. 5 show's the load deflection diagrams for the three polymers. The bold points in this figure represent the result of the finite element simulation for PVC (see Section 3). As noted previously, the restilt of the finite element analvsis matches the experimental results. Due to linear behaviour. it would be expected that the finite element simulation of the other materials would also match the experimental values.

Table 3 presents the comparative values of the shear moduli of PVC. PE-HD and PMMA obrained from the anticlastic plate bending tests along with those found from the torsion pendulum tests.

Table 3 - Comparison of results from the $A C P B$ tests with the torsion pendulum lests

\begin{tabular}{|c|c|c|}
\hline \multirow{2}{*}{ Material } & \multicolumn{2}{|c|}{ Shear modulus $\left[\mathrm{N} / \mathrm{mm}^{2}\right]$} \\
\cline { 2 - 3 } & Torsion pendulum test & ACPB test \\
\hline PVC.U & 1301 & 1240 \\
\hline PE-HD & 616 & 396 \\
\hline PMMA & 1575 & 1367 \\
\hline
\end{tabular}




\subsection{PUR foam}

Due to the cellular structure of foams, the preparation of small samples of foams and their tensile and torsion testing may involve some difficulty. Testing of foams with the $\mathrm{ACPB}$ testing method, on the other hand, proved to be simple and very efficient. Fig. 6 shows the average load-deflection curves for the PUR samples with various thicknesses.

The correlation factor for all PUR samples was found to be equal to 0.922. The shear modulus obtained with the $\mathrm{ACPB}$ method was compared with that of the torsion pendulum test. Table 4 summarizes the results of the two tests.

\section{TEMPERATURE-DEPENDENT TESTS}

Shear moduli and Poisson's ratios of polymers are temperature-dependent: it is known that an increase in temperature will generally result in a decrease in the shear niodulus of polymers. To explore the potential of the $\mathrm{ACPB}$ testing method for temperature-dependent tests. a number of tests at different temperatures were performed. The materials tested included PE-HD, PVC-U, and PMMA. Samples of these materials were taken from the same plates as those for the short-term test samples.

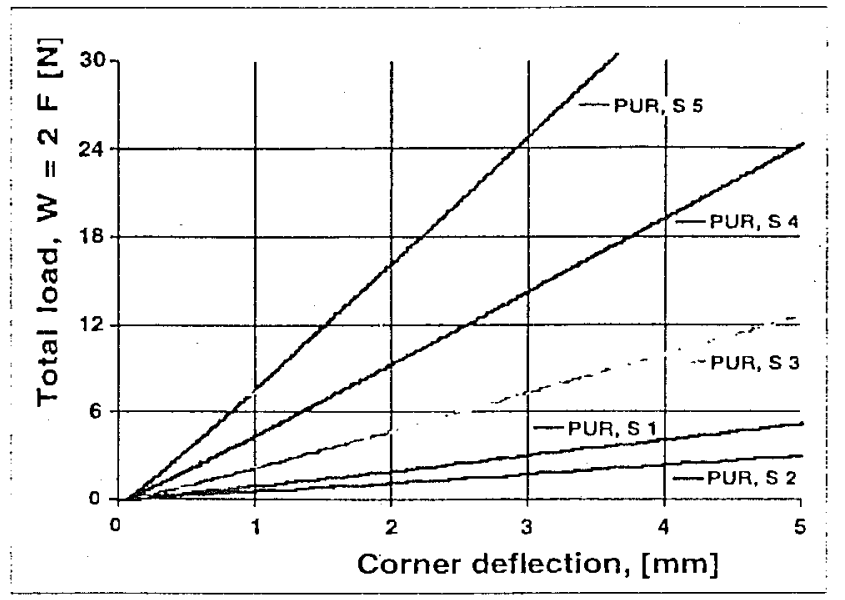

Fig. 6-Average load-deflection curves for PUR foam samples with various thicknesses.

Table 4 - Shear moduli derived from $A C P B$ tests and torsion pendulum tests on PUR foam

\begin{tabular}{|c|c|c|c|}
\hline \multirow[b]{2}{*}{ Sample } & \multirow[b]{2}{*}{$\begin{array}{l}\text { Thickness, } \\
\mathrm{h}[\mathrm{mm}]\end{array}$} & \multicolumn{2}{|c|}{ Shear modulus $\left[\mathrm{N} / \mathrm{mm}^{2}\right]$} \\
\hline & & $\begin{array}{c}\text { Torsion pendulum } \\
\text { test }\end{array}$ & $\begin{array}{c}\text { Anticlastic plate bending } \\
\text { test }\end{array}$ \\
\hline PUR S1 & 4.91 & 28.6 & 34.77 \\
\hline PUR S2 & 5.98 & 28.6 & 33.51 \\
\hline PUR S3 & 8.05 & 28.6 & 33.91 \\
\hline PUR S4 & 9.70 & 28.6 & 37.11 \\
\hline PUR S5 & 11.83 & 28.6 & 35.56 \\
\hline
\end{tabular}

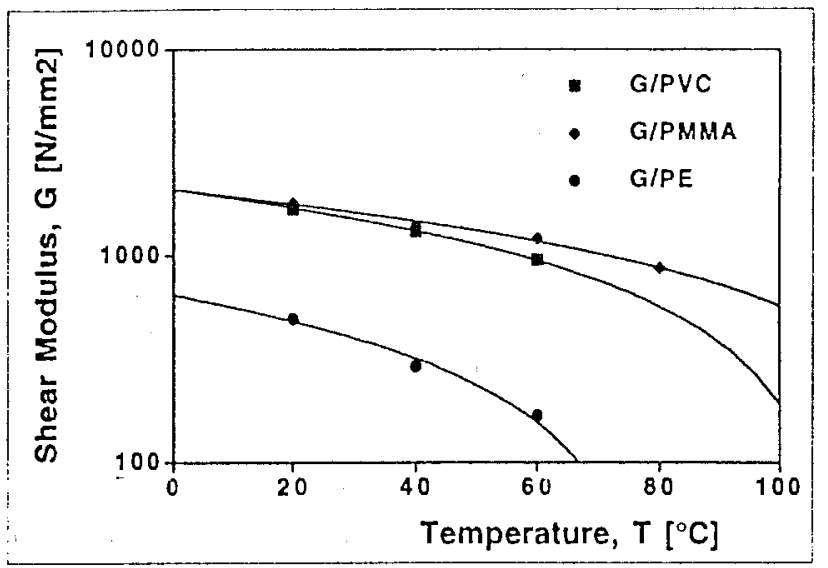

Fig. 7 - Shear modulus as a function of temperature for PE. PMMA and PVC-U.

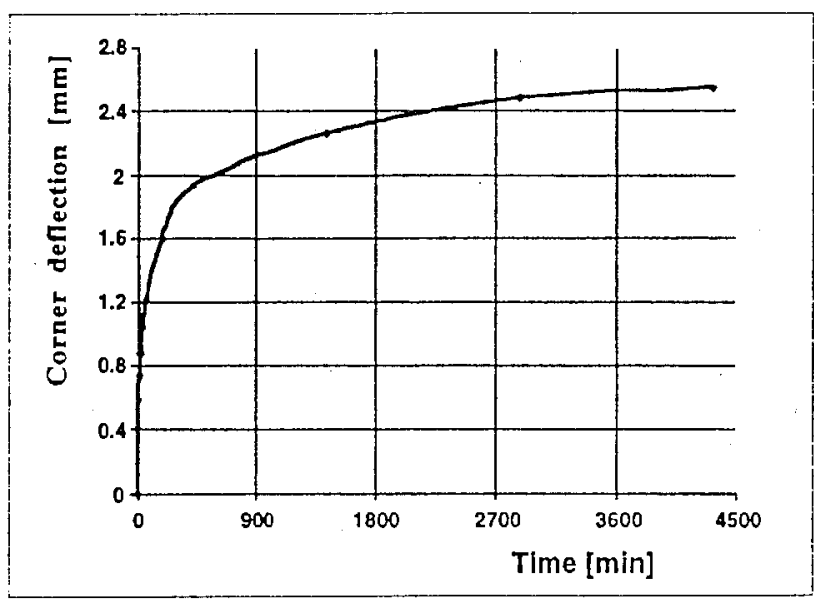

Fig. 8 - Corner deflection of the anticlastically-bent PE-HD plate as a function of time under a maintained load of 12.67 Newtons.

Various test samples were thermally conditioned to 23, 40,60 and 80 degrees; then, they were placed in the $A C P B$ device and their deflections under the applied load were measured. Fig. 7 represents the results of these tests. Curves were fitted to the experimental data; Fig. 7 show's the descending trend of all these curves.

\section{ACPB CREEP TEST OF POLYMERS}

To explore the potential of the constructed $\mathrm{ACPB}$ testing device for long-term tests, a series of long-term anticlastic bending tests on PE-HD were performed. During these tests, a constant load was maintained on the samples and the resulting deformation was measured at various time intervals. Fig. 8 shows the result of $\mathrm{ACPB}$ creep tests; it represents the corner deflection of the plate as a function of time.

Fig. 9 show's the long-term shear modulus of the PE$\mathrm{HD}$ material which was determined from the creep tests through a correlation with $\mathrm{ACPB}$ theory. 


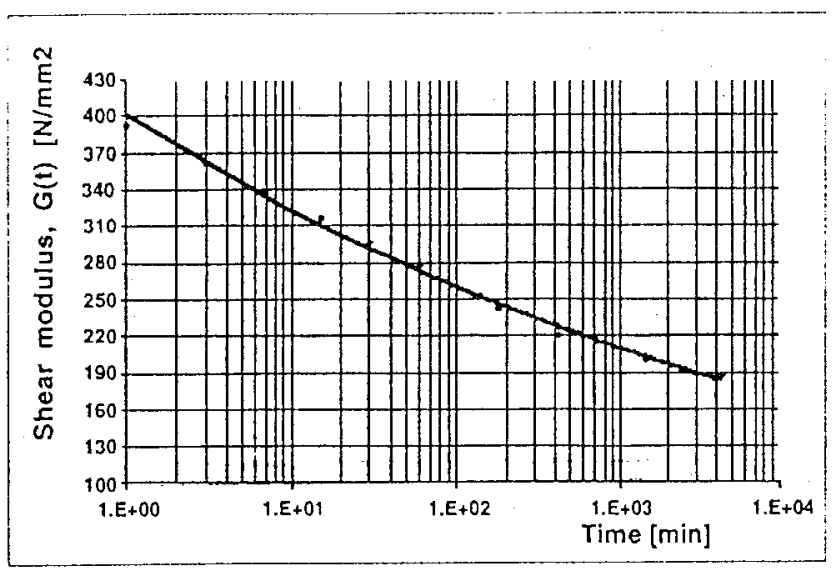

Fig. 9 - Time-dependent shear modulus of PE-HD obrained with the ACPB test.

\section{FURTHER TESTS}

To assess the intluence of loading. boundary conditions and geometrical parameters, a number of other tests were performed. Furthermore, in order to study the deformation due to indentation and the in-plane (membrane) effects, some subsidiary tests were also carried out. Moreover, to investigate local contact deformation due to cormer forces, samples from aluminium, steel and brass were subjected to indentation tests. It would be expected that, due to local plastification. the measured deflection in a real anticlastic test would be larger than the deflection in the ideal anticlastic bending. At the loading levels used for $\mathrm{ACPB}$ tests, however. the local plastification proved to be insignificant.

To evaluate the cable/membrane effects, which might lead to non-linear behaviour. a group of three-point bending tests on strips were also performed. In the three-point bending tests. the supports of the actual device were chosen and the loading was applied through a steel cylinder. At the lower level of loading, the loaddeflection curves of these strips showed a linear behaviour; no pronounced non-linearity was observed.

\section{DISCUSSION OF THE ACPB METHOD}

The main groal of the present work has been to introduce the well-known ACPB testing methodology in the area of polvmers and foams, and to extend it to the creep testing of these materials as well as to the determination of their temperature-dependent shear moduli.
The ACPB tes method proves to be particularly useful tor the testing of materials whose simple preparation and handling presents sone difficulties. Foams, in particular toams with an open cell structure, and some polymers are examples of such materials. Other features of the $\mathrm{ACPB}$ test device are its simple construction and portability; these features enable the construction of many of these devices at low cost for the long-term (time scale of several years) testing of polvmers and foams, along with the possibility of performing tempcraturedependent tests in small conditioning chambers.

A comparison of the results from the ACPB tests with those from the torsion pendulun tests has shown a certain degree of discrepancy; this may be attributed to differences in the sample prepararion procedure, size effects, testing speed, as well as the theories used for the processing of data. In order to fully investigate the influence in these parameters, additional comparative tests would be required.

The ACPB theory should be better refined to take into account the second-order effects arising from the boundary conditions and from the ample size. Furthermore, it should be noted that formula ( $t$ ) yields an average value for the $G$ modulus of the samples: this value may indecd characterize the shear modulus of the material itself. For anisotropic nlaterials, such as laminated and sandwich plates, however. this method can only give the overall torsional rigidity of the plate.

\section{REFERENCES}

(1) Farshad. M.. 'Design and Amlysis of Shell Structures' (Kluwer Academic Publishers. Dordrechr. 1992) page 5.

12) Biblis. E.J. and Lee. W.C.. Simplification of the experimental method for detemining plate shear modulus of plywood and particleboard. Forst Produti: fourmal $26(+)$ (1976) 38-t1.

[3] ASTM D3044. Seandard Te'se Method for Shear Modulus of Plywood (Ameracan Socicty for Testing and Materials. Philadelphia. 1976).

1+1 Timoshenko. S. and Woinowsky-Kriegcr. S., 'Theory of Plates and Shells". Chapeer 2 and 4 (Mi Graw-Hill. London. 1959).

15) Allen. H.G.. Analysis and Design of Structural Sandwich Panels" (Pergamon Press. 1969) 261-26.3.

[o] Donnel. L.H.. Beams. Plater and Shells' (M.Cinw-Hill. London. 1976) page $1+9$.

17) Giles Carter. F. and Donald. E.P. Materials Scicince and Enginesring i ASM Intemational, $1 \%)$ i.

|B| DIN 53+4. Prutung von polyneren Werkiteffen. Torsionsichwingursuch. Besuch. Berlin 1986.

(9) DIN 53455. Prutung von Kunststoffen. Zugiersuch. Beuch. Berlin. 198h. 


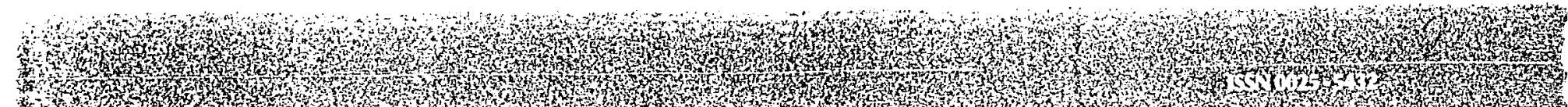

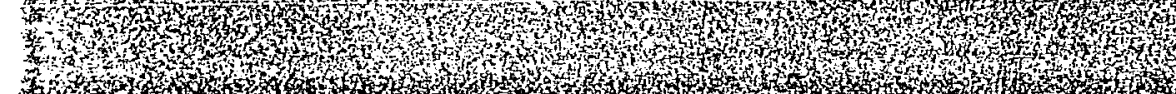

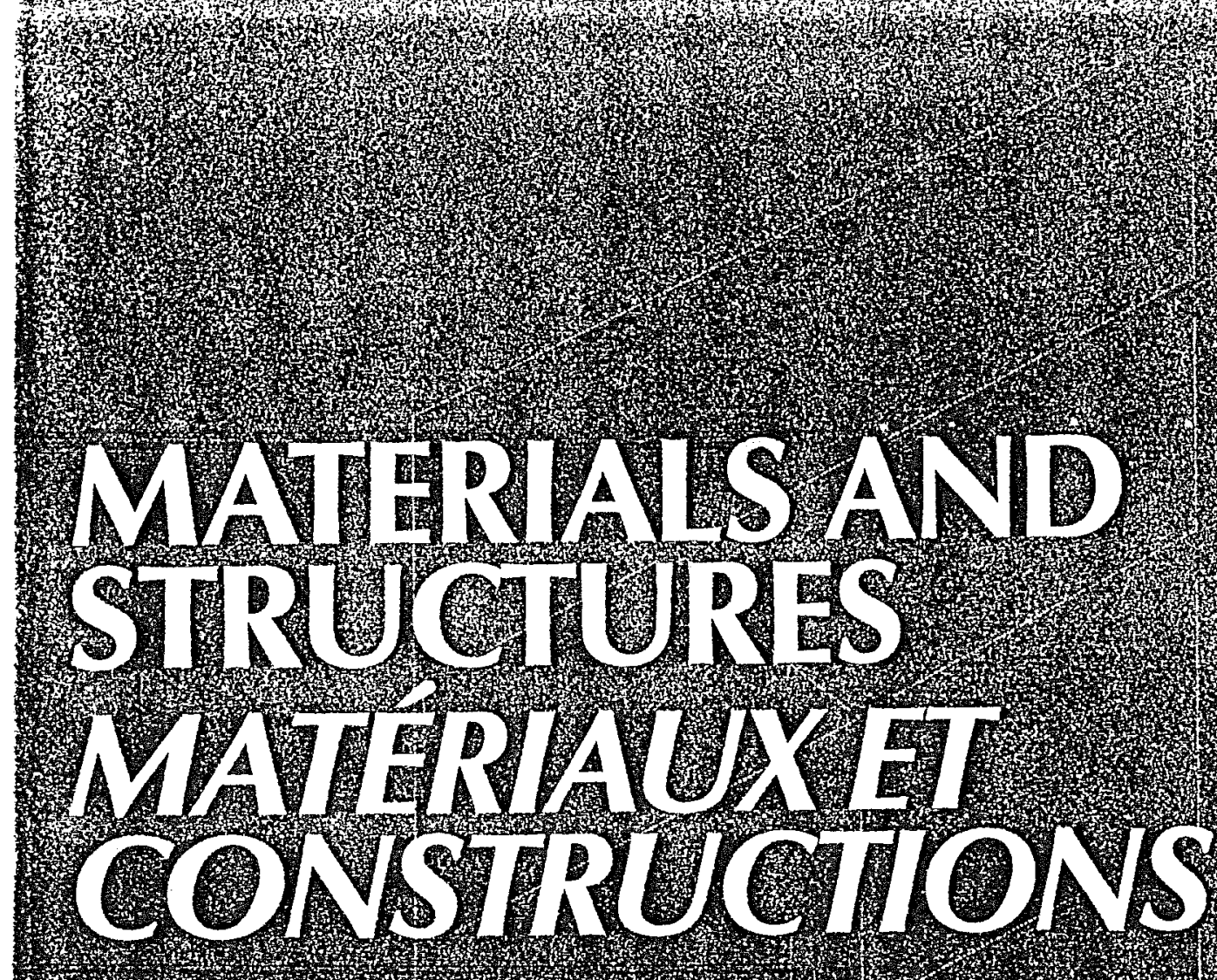

JULY 1997

(4) 11

N:201
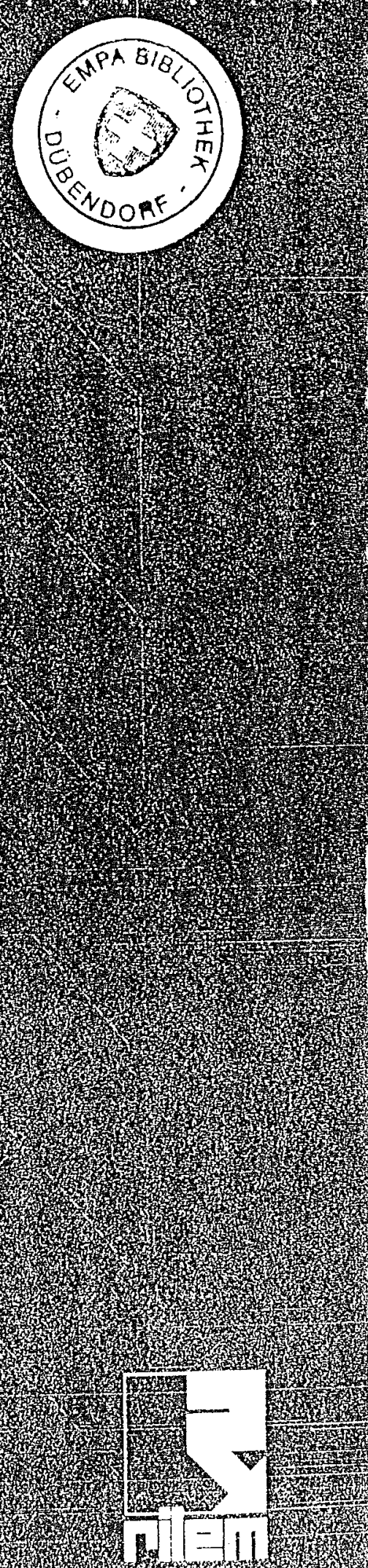